\title{
The role of undergraduate medical students training in respect for patient confidentiality
}

\author{
Cristina M Beltran-Aroca ${ }^{1}$, Rafael Ruiz-Montero ${ }^{2^{*}} \mathbb{D}$, Fernando Labella ${ }^{3}$ and Eloy Girela-López ${ }^{1}$
}

\begin{abstract}
Background: Encouraging professional integrity is vital for providing a standard of excellence in quality medical care and education and in promoting a culture of respect and responsibility. The primary objective of this work consisted of studying the relationship of medical students to the right to patient privacy in Spain, specifically by analysing the conditions for accessing patient clinical histories $(\mathrm{CHs})$.
\end{abstract}

Methods: A cross-sectional study was conducted based on a questionnaire sent by e-mail to final-year students at 41 Spanish universities. It had 14 multiple choice and closed questions framed in 3 large blocks. The first question addressed basic general knowledge issues on the right to privacy and the obligation for confidentiality. The two remaining blocks were made up of questions directed towards evaluating the frequency with which certain requirements and action steps related to students attending patients were performed and regarding the guarantees associated with accessing and handling patient $\mathrm{CHs}$ both on paper and in the Electronic Medical Record.

Results: A total of 245 valid replies were considered. A total of $67.8 \%$ of participants were women, with an average age of $24.05 \pm 3.49$ years. Up to $90.6 \%$ were aware that confidentiality affected the data in $\mathrm{CHs}$, although $43.3 \%$ possessed non-anonymized photocopies of patient clinical reports outside the healthcare context, and only $49.8 \%$ of the students were always adequately identified. A total of $59.2 \%$ accessed patient $\mathrm{CHs}$ on some occasions by using passwords belonging to healthcare professionals, $77.2 \%$ of them did not have the patients' express consent, and $71.9 \%$ accessed a $\mathrm{CH}$ that was not anonymised.

Conclusions: The role of healthcare institutions and universities is considered to be fundamental in implementing educational measures regarding the risks and ethical and legal problems arising from the use of $\mathrm{CHs}$ among professionals and students. A thorough study of medical ethics is needed through the analysis of clinical cases and direct exposure to situations in which the patient's confidentiality is questioned.

Keywords: Professionalism, Undergraduate, Medical students, Confidentiality, Ethical issues

\footnotetext{
* Correspondence: rafaelruizmontero@gmail.com

${ }^{2}$ Instituto Maimónides de Investigación Biomédica de Córdoba (IMIBIC),

Hospital Universitario Reina Sofía, Universidad de Córdoba, Avda. Menéndez Pidal s/n, 14004 Córdoba, Spain

Full list of author information is available at the end of the article
}

(C) The Author(s). 2021 Open Access This article is licensed under a Creative Commons Attribution 4.0 International License, which permits use, sharing, adaptation, distribution and reproduction in any medium or format, as long as you give appropriate credit to the original author(s) and the source, provide a link to the Creative Commons licence, and indicate if changes were made. The images or other third party material in this article are included in the article's Creative Commons licence, unless indicated otherwise in a credit line to the material. If material is not included in the article's Creative Commons licence and your intended use is not permitted by statutory regulation or exceeds the permitted use, you will need to obtain permission directly from the copyright holder. To view a copy of this licence, visit http://creativecommons.org/licenses/by/4.0/ The Creative Commons Public Domain Dedication waiver (http://creativecommons.org/publicdomain/zero/1.0/) applies to the data made available in this article, unless otherwise stated in a credit line to the data. 


\section{Background}

The right to privacy is inherent to human dignity. Together with freedom and private life, it signifies respect for the individual's autonomy [1]. Without an expectation of privacy, patients might not disclose important information or may avoid seeking care, fearing a loss of employment or stigmatization [2]. The rights to privacy and the protection of health data deserve particular respect in the healthcare environment [3]. This duty primarily falls on the healthcare professional in charge of attending the patient, but we cannot obviate the fundamental role of universities and healthcare institutions in training future professionals. It is crucial to promote professional integrity with the aim of providing a standard of excellence in care quality and at a medical education level, of fostering a culture of respect and responsibility [4]. Various publications have noted the importance conferred by medical students to the patient's right to privacy [5-7]. In Spain, a considerable number of students come into contact with patients and their respective personal data through clinical practice sessions in different healthcare centres. This characteristic inspired the publication of the Patient Privacy Protocol in 2017 [8], in which promoting respect for patient confidentiality stands out, and it affects all health sciences students $[9,10]$. The obligation of medical students is to respect the confidentiality of the information contained in the clinical history $(\mathrm{CH})$ of patients strictly, regardless of its use. The exemplary duty of those responsible for clinical teaching should be added when considering that any medical act enshrines an important ethical value at all times [11]. They should supply the students with all the opportunities necessary for learning professionalism during clinical practice classes, taking maximum advantage of the value of the hidden curriculum [12].

The primary objective of this work consisted of studying the relationship of medical students to the right to patient privacy. Specifically, specific assumptions were analysed with respect to the conditions of access to information in $\mathrm{CHs}$ by means of a questionnaire that we prepared.

\section{Methods}

A cross-sectional, descriptive, and observational study was conducted based on a questionnaire sent to students who were doing their clinical practice sessions in the final year (6th ) of medicine studies at 41 Spanish universities. The reference population comprised all 6th -year medicine students in Spain during the 2019/20 academic year, who began their studies in 2014/2015. In $2014 / 15,7,127$ people enrolled in the degree in medicine in Spain, according to data from the Ministry of Science, Innovation and Universities [13]. Through this source, the reference population was obtained by the university. A sample by quotas (university) was conducted to ensure the correct distribution of the sample obtained in the survey. A sample size composed of the sum of the quotas was calculated. In a random sample, 258 individuals were sufficient to estimate with a $95 \%$ confidence level, a population percentage of approximately $50 \%$.

A first draft of the questionnaire was submitted to a panel of experts that was composed of 4 doctors. After their suggestions for revision were received, the questionnaire was revised and modified. Next, the questionnaire was evaluated by means of a pilot survey from 20 students of medicine at the University of Córdoba, resulting in another series of changes that were related to some of the practical aspects of its administration. Responses from a pilot study were excluded from the final statistical analysis. To recruit participants, a final questionnaire was sent to students by e-mail. An anonymous answer stored in computerized form was generated automatically, to which only the experts had access. The period for turning in the sample was from November 2019 to March 2020.

The questionnaire included a series of sociodemographic characteristics: sex, age, and the university at which the participant performed their practical work during the 2019/20 academic year. The questionnaire (see Additional file 1) had 14 multiple choice and closed questions. Some of them were directly related to the $\mathrm{Pa}$ tient Privacy Protocol with regard to student respect for the right to the privacy of the patient, and they were framed in 3 blocks. The first one was made up of the first two questions (Q-no. 1-2) and addressed general knowledge issues on the right to privacy and the obligation of confidentiality. The two remaining blocks were made up of questions directed towards evaluating the frequency (always, often, sometimes, seldom, or never) with which specific action requirements related to the students were performed when attending a patient (Qno. 3-8) and regarding the guarantees in accessing and managing their $\mathrm{CH}$ both on paper and in the Electronic Medical Record (EMR) (Q-no. 9-14). It was presented in four languages: Spanish, Catalan, Galician and Basque.

The questionnaire and methodology for this study were performed in accordance with the Declaration of Helsinki and were approved by the Human Research Ethics Committee of the University of Córdoba (Spain) (Ref. No. CEIH-20-21). Students were told that their participation in the study was voluntary and that there was a guarantee of confidentiality and anonymity. Additionally, our study adheres to STROBE guidelines (see Additional file 2) for reporting observational research.

A statistical analysis was performed with PASW Statistics 25 software $\left(\right.$ IBM SPSS $\left.{ }^{\circledR}\right)$. In addition to the 
descriptive analysis, a comparison of proportions was made between the different groups by Chi-squared ( $\mathrm{x} 2$ ) tests for contingency tables. Lastly, a binomial logistic regression or an ordered logistic regression was conducted, as appropriate, according to sex (crude) and sex + age (adjusted odds ratios). The values considered to be statistically significant were those with a level of confidence of over $95 \%(p<0.05)$. A quality control was performed to ensure that the resulting sample had a similar distribution of frequencies per age group and sex compared to that of the reference population.

\section{Results}

Of the 7,127 students entering the degree in medicine during the 2014/15 academic year, $6.7 \%(N=474)$ fully answered the questionnaire in 2019/20 (incomplete questionnaires were not evaluated). A random selection was made to study the number of respondents representing each university according to the number of places offered, reaching a total of 245 valid responses. A total of $90.2 \%(n=37)$ of the 41 universities satisfied the optimal amount required for the questionnaires, but we did not receive any response from $7.3 \%$ of them $(n=3)$ (Table 1). The general data in the sample were representative of the population that we started from; $67.8 \%$ $(n=166)$ of the participants were women, and the average age was $24.05 \pm 3.49$ years old (range 19-56).

\section{Learning professional values}

The first question refers to the right to privacy. Up to $88.2 \%$ answered that they were familiar with the confidential nature of health data as well as the idea that information that patients had revealed and confided to them was private $(73.9 \%)$. A total of $61.2 \%$ responded correctly, i.e., indicating all the options, but no statistical significance was observed in terms of the participant's $\operatorname{sex}(p=0.889)$.

When asked about the obligation of confidentiality in Q-no. 2, 76.7\% correctly marked all the options, with statistical significance being observed in favour of men $(p=0.042) \quad$ (Table 2). The majority percentage came from the option contained in the $\mathrm{CH}(90.6 \%)$, followed by maintaining that obligation even after the death of the patient $(89.4 \%)$.

\section{Requirements of action to be followed when attending patients}

For Q-no. 3, 78.8\% affirmed having signed a commitment of confidentiality during their practical exercises.

When asked whether they knew the person in charge of supervising their practical classes in Q-no. 4, and $75.9 \%$ answered positively as a fact that occurred regularly.
For Q-no. 5, 73.5\% claimed to wear an identification tag usually during their practice classes, and no statistical significance was observed in relation to the sex of the subject $(p=0.702)$ (Fig. 1). However, in Q-no. 6, most of those who admitted not always wearing it $(n=$ 123 ) indicated that this action did not trigger any negative consequence for them from their tutor (90.2\%).

In Q-no. 7, 49\% reported that patients could often identify them as a student to an adequate extent, and $25.7 \%$ only sometimes (Fig. 1). Among those students who usually wore identification, $71.1 \%$ were generally identified by patients $(p=0.002)$ (Fig. 2).

When asked whether there were more than 4 students attending a patient at the same time in Q-no. 8, they answered that it was rare $(67.7 \%)$ (Fig. 1).

\section{Guarantees in accessing clinical history}

For Q-no. 9, $59.2 \%(n=145)$ stated that they had accessed the EMR of patients using an authentication mechanism supplied by a healthcare professional. This response was more frequent among men $(p=0.045)$ (Table 2). Only $16.6 \%$ of them had obtained the patient' s consent (Q-no. 10).

In Q-no. 11, 71.9\% of the students referred to accessing patients' $\mathrm{CHs}$ with personal data dissociated from clinical data occasionally. No statistical significance ( $p=$ 0.945) was found with respect to those who had accessed the CHs.

For Q-no. $12,43.3 \% \quad(n=106)$ possessed nonanonymized photocopies of the patient's clinical record outside the health centre. No significant differences were observed between those who possessed photocopies and those who answered questions $1(p=0.188)$ and $2(p=$ $0.649)$ correctly. Only $10.4 \%$ of those who claimed to have this type of photocopies claimed to have the patients' express consent (Q-no. 13).

For students who answered Q-no. 14 because their Final Year Project (FYP) involved the use of patient clinical databases for research $(n=136), 49.3 \%$ indicated that the given data were anonymized (Fig. 3).

All the previously described results were adjusted for sex and age. The values are shown in Table 2.

\section{Discussion}

\section{Learning professional values}

The World Federation for Medical Education emphasizes the need to balance the academic capacities and the behaviours of medical students. The aim is to assist them in undertaking life-long learning and demonstrating their professionalism in the different roles of a doctor [14]. Professionalism includes respect for the confidentiality of patients, which is one of the basic skills that they have to develop and maintain both as 
Table 1 Questionnaires $(\mathrm{Q})$ requested and ultimately received in accordance with the number of places offered by each university

\begin{tabular}{|c|c|c|c|c|c|}
\hline & Places offered $^{a}$ & Q. $R \epsilon$ & & Q. R & \\
\hline & & $\mathrm{n}$ & $\%$ & $n$ & $\%$ \\
\hline Universidad Alfonso X el Sabio & 120 & 4 & 1.6 & 4 & 1.6 \\
\hline Universidad Autónoma de Madrid & 275 & 10 & 3.9 & 10 & 3.9 \\
\hline Universidad Católica de Murcia & 90 & 3 & 1.2 & 3 & 1.2 \\
\hline Universidad Católica de Valencia & 119 & 4 & 1.6 & 4 & 1.6 \\
\hline Universidad CEU Cardenal Herrera & 120 & 4 & 1.6 & 4 & 1.6 \\
\hline Universidad CEU San Pablo & 160 & 6 & 2.3 & 6 & 2.3 \\
\hline Universidad Complutense de Madrid & 320 & 12 & 4.7 & 12 & 4.7 \\
\hline Universidad de Alcalá & 373 & 14 & 5.4 & 14 & 5.4 \\
\hline Universidad de Cádiz & 155 & 6 & 2.3 & 6 & 2.3 \\
\hline Universidad de Cantabria & 120 & 4 & 1.6 & 4 & 1.6 \\
\hline Universidad de Castilla La Mancha (Albacete) & 115 & 4 & 1.6 & 4 & 1.6 \\
\hline Universidad de Castilla La Mancha (Ciudad Real) & 60 & 2 & 0.8 & 2 & 0.8 \\
\hline Universidad de Córdoba & 120 & 4 & 1.6 & 4 & 1.6 \\
\hline Universidad de Extremadura & 120 & 4 & 1.6 & 4 & 1.6 \\
\hline Universidad de Granada & 253 & 9 & 3.5 & 9 & 3.5 \\
\hline Universidad de la Laguna & 130 & 5 & 1.9 & 5 & 2.0 \\
\hline Universidad de las Palmas de Gran Canaria & 135 & 5 & 1.9 & 5 & 2.0 \\
\hline Universidad de Málaga & 170 & 6 & 2.3 & 6 & 2.3 \\
\hline Universidad de Murcia & 200 & 7 & 2.7 & 7 & 2.7 \\
\hline Universidad de Navarra & 210 & 8 & 3.1 & 8 & 3.1 \\
\hline Universidad de Oviedo & 150 & 5 & 1.9 & 0 & 0 \\
\hline Universidad de Salamanca & 203 & 7 & 2.7 & 7 & 2.7 \\
\hline Universidade de Santiago de Compostela & 350 & 13 & 5.0 & 13 & 5.0 \\
\hline Universidad de Sevilla & 320 & 12 & 4.7 & 12 & 4.7 \\
\hline Universidad de Valladolid & 185 & 7 & 2.7 & 7 & 2.7 \\
\hline Universidad de Zaragoza & 230 & 8 & 3.1 & 8 & 3.1 \\
\hline Universidad del País Vasco & 270 & 10 & 3.9 & 10 & 3.9 \\
\hline Universidad Europea de Madrid & 200 & 7 & 2.7 & 7 & 2.7 \\
\hline Universidad Francisco de Vitoria & 120 & 4 & 1.6 & 4 & 1.6 \\
\hline Universidad Internacional de Catalunya & 90 & 3 & 1.2 & 2 & 0.8 \\
\hline Universidad Miguel Hernández & 130 & 5 & 1.9 & 5 & 1.9 \\
\hline Universidad Rey Juan Carlos & 150 & 5 & 1.9 & 5 & 1.9 \\
\hline Universitat Autònoma de Barcelona & 320 & 12 & 4.7 & 12 & 4.7 \\
\hline Universitat de Barcelona (C. Bellvitge) & 140 & 5 & 1.9 & 5 & 1.9 \\
\hline Universitat de Barcelona (C. Clínic) & 119 & 4 & 1.6 & 4 & 1.6 \\
\hline Universitat de Girona & 80 & 3 & 1.2 & 3 & 1.2 \\
\hline Universitat de Lleida & 120 & 5 & 1.9 & 0 & 0 \\
\hline Universitat de València & 320 & 12 & 4.7 & 12 & 4.7 \\
\hline Universitat Jaume I & 80 & 3 & 1.2 & 3 & 1.2 \\
\hline Universitat Pompeu Fabra & 60 & 2 & 0.8 & 0 & 0 \\
\hline Universitat Rovira i Virgili & 125 & 5 & 1.9 & 5 & 1.9 \\
\hline Total & 7127 & 258 & 100 & 245 & 100 \\
\hline
\end{tabular}

aPlaces offered by each University in the academic year 2014/15 
Table 2 Crude and adjusted odds ratios (and $95 \%$ confidence intervals) from logistic regression analyses for identifying associations between question, sex, and age

\begin{tabular}{|c|c|c|c|c|c|c|}
\hline & \multicolumn{2}{|c|}{ Crude odds ratio } & \multicolumn{4}{|c|}{ Adjusted odds ratio } \\
\hline & \multicolumn{2}{|l|}{$\begin{array}{l}\text { Sex } \\
\text { (ref = Female) }\end{array}$} & \multicolumn{4}{|l|}{$\begin{array}{l}\text { Sex }+ \text { Age } \\
(\text { ref }=\text { Female })\end{array}$} \\
\hline & Sex & $\mathbf{p}$ & Sex & p & Age & $\mathbf{p}$ \\
\hline Q1. Right to privacy & $1.05(0.60-1.83)$ & 0.859 & $1.04(0.60-1.82)$ & 0.885 & $1.01(0.94-1.10)$ & 0.727 \\
\hline Q2. Obligation of confidentiality & $2.08(1.05-4.35)$ & $0.042^{*}$ & $2.16(1.09-4.56)$ & $0.034^{*}$ & $0.96(0.88-1.04)$ & 0.276 \\
\hline Q3. Commitment to confidentiality & $0.97(0.48-2.01)$ & 0.931 & $0.93(0.46-1.94)$ & 0.839 & $1.10(0.97-1.36)$ & 0.286 \\
\hline Q4. Student knows the tutor & $1.24(0.75-2.06)$ & 0.400 & $1.24(0.75-2.06)$ & 0.402 & $1.00(0.93-1.08)$ & 0.998 \\
\hline Q5. Wearing an identification tag & $0.88(0.53-1.46)$ & 0.615 & $0.84(0.51-1.40)$ & 0.506 & $1.08(1.00-1.21)$ & 0.110 \\
\hline Q6. Negative consequences & $1.81(0.49-6.40)$ & 0.353 & $1.94(0.52-6.94)$ & 0.303 & $0.84(0.53-1.14)$ & 0.421 \\
\hline Q7. Patient knows you are a student & $1.21(0.73-2.01)$ & 0.471 & $1.19(0.72-1.99)$ & 0.496 & $1.04(0.97-1.11)$ & 0.303 \\
\hline Q8. More than 4 students & $0.96(0.59-1.57)$ & 0.868 & $0.95(0.58-1.56)$ & 0.839 & $1.05(0.95-1.16)$ & 0.361 \\
\hline Q9. Access to patient EMR & $1.78(1.02-3.16)$ & $0.045^{*}$ & $1.75(1.00-3.12)$ & 0.052 & $1.03(0.95-1.13)$ & 0.519 \\
\hline Q10. Consent of the patient to access & $0.80(0.34-1.79)$ & 0.598 & $0.72(0.30-1.64)$ & 0.445 & $1.11(1.00-1.27)$ & 0.068 \\
\hline Q11. Access to patients dissociated $\mathrm{CH}$ & $0.89(0.54-1.47)$ & 0.657 & $0.88(0.53-1.45)$ & 0.624 & $1.03(0.95-1.12)$ & 0.624 \\
\hline Q12. Non-anonymized photocopies & $1.15(0.67-1.97)$ & 0.616 & $1.15(0.67-1.98)$ & 0.609 & $1.00(0.92-1.07)$ & 0.899 \\
\hline Q13. Consent of the patient to have photocopies & $1.17(0.40-3.23)$ & 0.770 & $0.79(2.28-2.39)$ & 0.686 & $1.33(1.07-1.73)$ & 0.024 \\
\hline Q14.Anonymisation for FYP & $1.50(0.82-2.85)$ & 0.198 & $1.49(0.81-2.84)$ & 0.207 & $1.01(0.93-1.12)$ & 0.817 \\
\hline
\end{tabular}

undergraduate medical students and as doctors during their professional careers [15].

A total of $88.6 \%$ of the respondents were aware that the obligation of confidentiality affected the most intimate physical and mental health data, also when considering the contents of $\mathrm{CHs}(90.6 \%)$, such as the results of medical examinations, complementary tests, or genetic data. The constant development of genetic testing technologies has promoted the objective that medical students know about the special protections for these data to avoid any type of discrimination in the family, social or work environment [16]. Notably, it also includes any

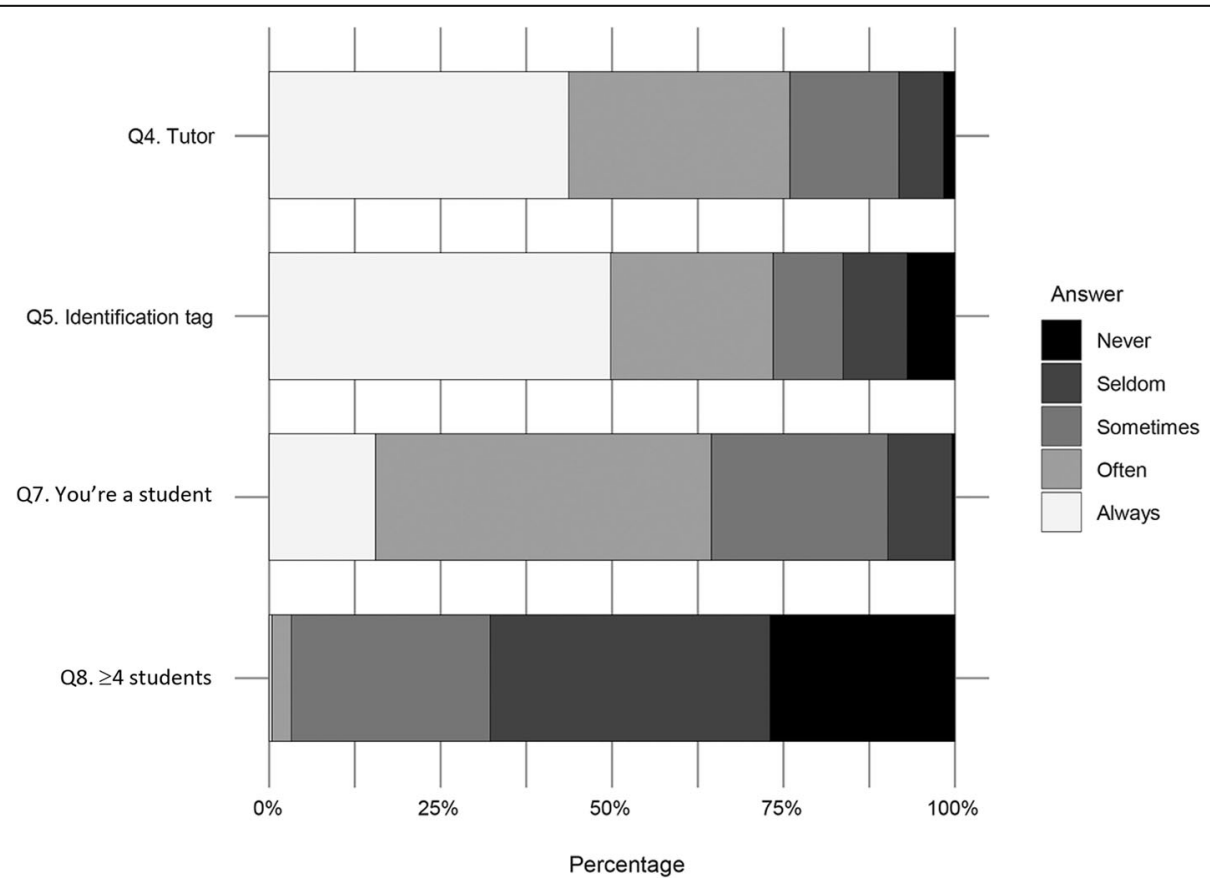

Fig. 1 Frequency of the requirements demanded with respect to students when attending patients. Q: question 


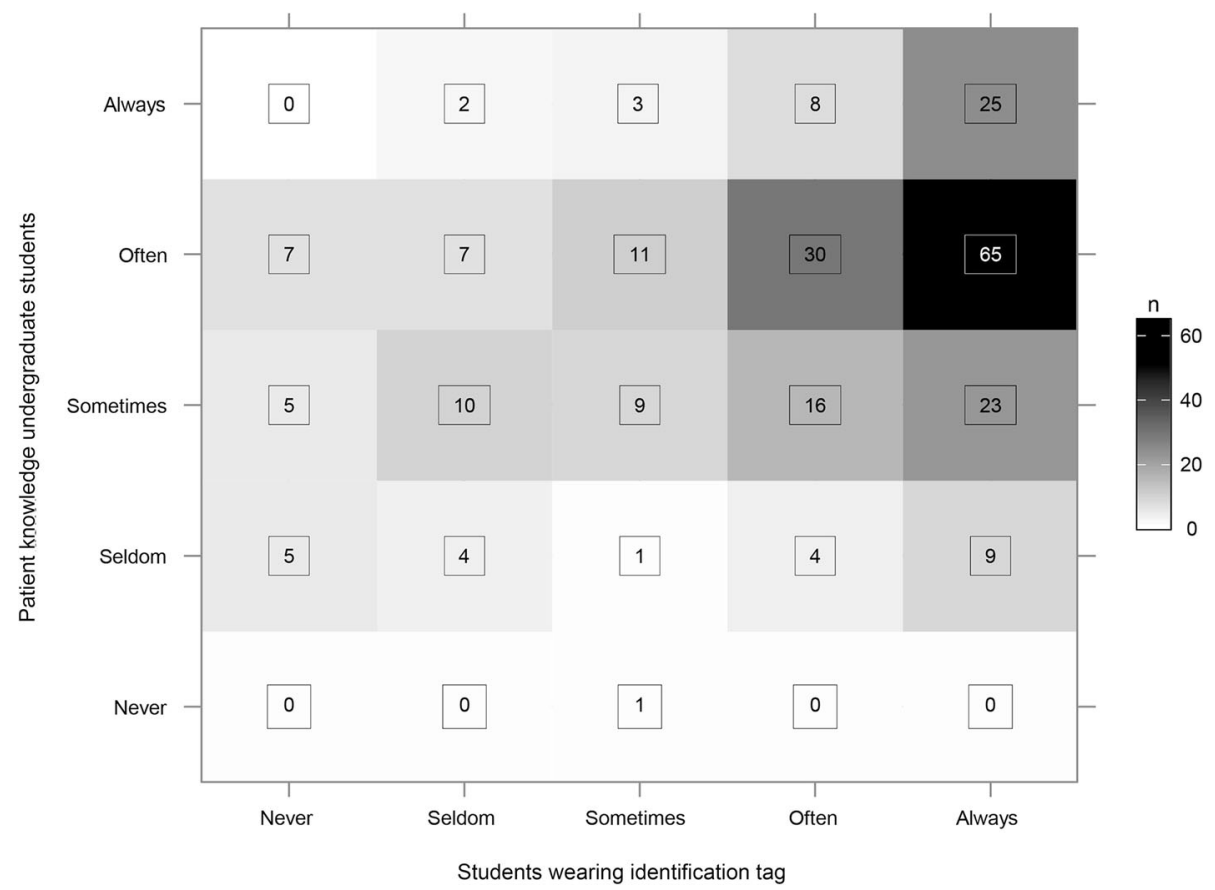

Fig. 2 Frequency with which patients identify the students from their identification tag $\left({ }^{*} p=0.002\right)$

information assigned to a physical person for health purposes that identifies them univocally [17]. The question about this issue had a majority response, although it was not frequently selected by the students $(85.7 \%)$. Recently, some deficiencies have been described in relation to knowledge about the obligation of confidentiality [7,
$18,19]$. Other authors mention final-year students who show little respect for patient confidentiality compared to other obligations, which is more marked in male students [20]. However, in this study, the men responded significantly more correctly to the concept of confidentiality. In recent decades, the teaching of medical ethics

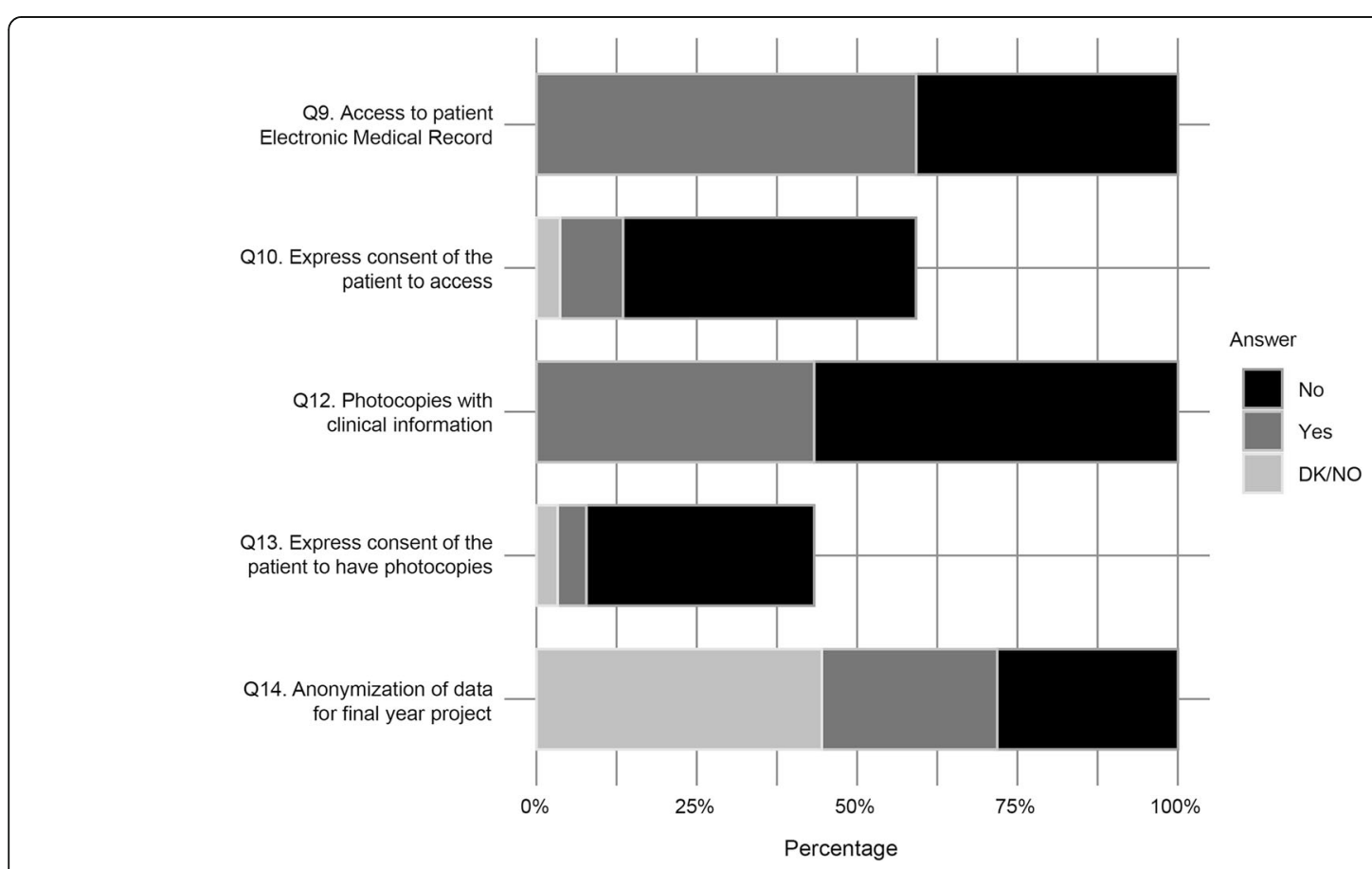

Fig. 3 Access to and management of clinical documentation by the student. Q: question 
has been implemented as a priority in the undergraduate curriculum of medical schools worldwide. Social changes and further developments in science and technology have contributed decisively to this change [21]. Moreover, it has become evident that medical students lose their ability to recognize ethical dilemmas and to address these situations with empathy and moral reasoning during medical education [22]. The need to reinforce competency-based education [23] in study plans has been proposed as well as implementing measures oriented towards developing the study of medical ethics. This subject presents some differentiated characteristics, so it would be necessary to go deeper into the analysis of professional conduct guides [18]. It is not suggested that medical schools replace more traditional bioethical theoretical teaching with the teaching of everyday ethics but rather to consider it a necessary supplement [24]. Thus, theoretical training is recommended, which is based on the analysis of clinical cases in which problems related to confidentiality arising in clinical practice are posed as well as direct exposure to situations in which the patient's privacy is questioned $[25,26]$.

\section{Requirements of action to be followed when attending patients}

Medical students confirm their obligation to respect the human dignity, freedom of choice and privacy of the patient [17] by signing a commitment to confidentiality at the beginning of the practice exercise period in their healthcare institution. The schools of medicine should inform the healthcare institution about the students who are going to do practice exercises. Most of the participants did so, although a non-negligible percentage admitted that they had not (17.1\%).

According to the principle of distributive justice, the benefits and burdens of health care, research, and education should fall fairly on all members of society. Society expects competent and well-trained health professionals. The direct intervention of students in patient health is a key element, because current patients are likely to benefit from the previous experiences of these practitioners [27]. Thus, it would be vital for both the patients and healthcare professionals to be aware of the presence of persons in training during patient attendance and that the institution takes on the responsibility of giving the student a card/tag permitting their identification [8]. Patients confer great importance to knowing who is participating in the medical process [28], and this study shows that only approximately half of the students were always suitably identified, and a large number of them who did not wear the tag $(90.2 \%)$ did not refer to any negative reactions from their tutor. The presence of students may also be a conditioning factor, which raises different opinions. Some professionals contend that patients cannot refuse their intervention in an educational institution such as a university teaching hospital, whereas others believe that there is a direct presumption of patient consent if the latter does not actively oppose it. The Protocol demands that express consent should be obtained authorizing their presence during medical attendance and that their number should be limited in attending the same patient [8]. Most patients usually accept the participation of students [29], although in certain specialist treatments, the patient's response could be conditioned by their sex [30]. This study did not permit us to make that inference, but $64.5 \%$ declared that the patients usually expressly knew that they were students, and this knowledge was significantly related to wearing a tag.

To ensure the fulfilment of all the described requirements, the healthcare institution itself will designate a tutor who will be the person of reference whom the student should address [8]. Since honesty has been found to be essential in the doctor-patient relationship, tutors should disclose and honestly explain the role of anyone who is present during a medical encounter, indicating those who are present for education as a medical professional [27]. Despite the circumstances in the healthcare system not always being favourable, the figure of the tutor is considered to be highly relevant [30], not only as a supervisor but also for feedback and assessment work with the student when acquiring practical skills in a safe and thoughtful atmosphere [31, 32]. A total of $75.9 \%$ of the participants usually knew who the tutor in charge was during the practice exercises, which was especially positive.

\section{Guarantees in accessing clinical history}

The $\mathrm{CH}$ is an instrument that is fundamentally aimed at guaranteeing adequate attendance of the patient. Digital support permits better legibility and accessibility and a more efficient and accurate organization of the data with respect to those on paper [33]. The Protocol expressly prohibits EMR access to students [8]. The reasons could be based on the fact that in $\mathrm{CHs}$ on paper, it is not possible to look for the records of different patients at the same time or for several medical attendance episodes in the same individual, or easily duplicate or edit the data [34]. These results contrasted significantly with the legal precepts, since over half of the participants indicated that they accessed the $\mathrm{CH}$ of patients on some occasions (59.2\%) without the patients' express consent (77.2\%).

In countries such as Germany, some hospitals have facilitated the use of $\mathrm{CHs}$ to final-year students [35]. Similarly, in the United Kingdom, the team in charge of attending the patient, including the students, can access the $\mathrm{CH}$ without the patient's express consent $[34,36]$. In the United States, this action has been permitted for 
years [37], and it increased to $96 \%$ of the centres in 2016. Guimarães et al. [38] made various proposals for encouraging the use of $\mathrm{CHs}$ among students in Portugal. In countries in which standard access is authorized, it is generally considered an advantageous tool for the learning process $[39,40]$. Having this access permits longterm follow-up of patients from diagnosis up to treatment, even once the direct relationship is over. However, this post-control has caused some ethical reactions related to the duty of training students in the right to privacy and autonomy of patients [41-43]. Students must access the $\mathrm{CH}$ to develop their abilities in $\mathrm{CH}$ use and maintenance and to understand the nuances of the EMR itself during a medical consultation [44]. Moreover, the handling of the $\mathrm{CH}$ is analogous to learning based on clinical cases, so that, in addition to promoting good professional conduct, it permits more active participation by the student in their training by directly applying theoretical knowledge to real cases [45-47]. This approach translates into the doctor's social duty (distributive justice) of caring for and obtaining maximum benefits (beneficence) for all the patients. The duty to protect the patient and, at another level, to protect the medical profession is based on trust and requires honesty, integrity and dignity [48]. Therefore, although the above advantages are numerous and obvious, other authors have stated that this type of action may be potentially harmful for the patient [48]. Illegal disclosures and unethical conduct have been described as potential dangers of student misuse of $\mathrm{CH}$ access in relation to patient privacy [49]. Observing the principle of nonmaleficence implies that the interest of the patient should be prioritized in the absence of a clear, additional benefit to the educational objectives of the student [50].

Restricting complete access to the entire evolution of the patient and assigning levels according to the year of the student's training [34] have been proposed for establishing some limits guaranteeing the educational objective. However, these premises should, in turn, safeguard the patient's autonomy [45, 51]. Therefore, rather than directly constraining access, the ultimate solution to the problem could be the same as in the countries where it is permitted, i.e., to request the patient's consent.

One notable aspect in this study as previously described is that students accessed the patient's $\mathrm{CH}$ by employing the authentication mechanism of a health professional [52]. This aspect clearly emphasizes the vulnerability of the health system, which is becoming increasingly complex and fragmented, and in which the quality and safety in attending patients have become the principal foci of attention [53]. Spanish legislation does not even contemplate student access to these records, so it does not propose solutions to these problematic types of situations. In the United Kingdom, a similar phenomenon was described in primary medical care attention, so there was a proposal to assign a unique digital identity to each student that leaves an indelible and identifiable mark and is therefore susceptible to being traced [34]. To counteract the above-described conduct, it is a priority for healthcare institutions to apply educational and even motivational measures [54] to take responsibility for the risks and ethical and legal problems arising from their employment by students [52, 55, 56]. Specifically, simulation experiences and "train the trainer" models, both for students and professionals, are considered effective methods of managing ethical challenges through education and the dissemination of evidence-based EMR strategies [57].

The law is somewhat more flexible with regard to the records kept on paper. The present data reveal the high frequency with which most of the students (71.9\%) could reach the $\mathrm{CHs}$ without the personal and clinical data of the patients being previously dissociated, something that is contrary to pre-established norms. The aim is to preserve anonymity unless the patients themselves have expressly consented to data access, which would seem to be the definitive solution so that the student's training is not undermined. If the use of this information has a teaching objective, the anonymization of the $\mathrm{CH}$ is also mandatory, although only $49.3 \%$ alleged that they received anonymized clinical data from patients to perform their FYP [8].

Another controversial aspect is that students have information about patients outside the healthcare centre. It is a problem that partially arises due to constant technological advances, which have favoured the storage of information and images in mobile devices such as phones, tablets, USB flash drives or laptops among the students themselves [58]. This practice poses a challenge to professionalism [59] and involves concerns related to both the privacy of the patient and consent to the availability of such data [60]. Although this paper does not explore the aforementioned issue, it is highly recommended to take strong measures to protect personal data when using such devices, expressly restricting the sharing of information through social media platforms [61], health information systems [62] or computer programs that are not subject to the security systems of healthcare centres $[8,63]$. However, with respect to the data on paper, this work did show that approximately $43 \%$ of the students disposed of copies of non-anonymized patient $\mathrm{CH}$ reports outside the healthcare sphere, in most cases without obtaining the patients' consent $(82.1 \%)$. The frequency of this phenomenon was not consistent with the fact that a very high percentage 
Table 3 Key points and recommendations

- The Spanish Patient Privacy Protocol promotes respect for patient confidentiality among all Health Sciences students.

- Medical students were aware of the obligation of confidentiality although a high percentage possessed copies of non-anonymized patient $\mathrm{CH}$ reports outside the healthcare environment and were not always adequately identified.

- Despite restrictions on access to patients' $\mathrm{CHs}$, more than half of the students used a health professional's password without the prior express consent of patients and mostly without the anonymization of the $\mathrm{CHs}$.

- The role of university centres together with healthcare institutions is to promote theoretical training related to confidentiality and guarantee continuing medical education.

- A more feasible approach would be recommendable to ensure the educational objective of having access to $\mathrm{CHs}$ by establishing a direct protocolized request to ask for the patient's consent.

(90.6\%) of them were aware of the obligation of confidentiality that protected those data. Although the copies were probably supplied by the doctor in charge of the patient, the students accessed that material outside the healthcare institution. The fact that they took part in these scenarios could be the cause of the students having a greater tendency to consider certain unprofessional acts as being acceptable behaviour after their practical work [64]. Situations in which patient privacy and confidentiality are compromised have been described as a frequent event among healthcare professionals. Consequently, several studies have noted the importance of implementing continuing medical education based on greater care and management of clinical information [65, 66]. Hence, the importance of the hidden curriculum throughout pre-degree training is clear so that the students incorporate modes of behaviour taken from those of their professors/tutors beyond the contents of the formal curriculum.

This study has several limitations. The response rate was suboptimal, probably due to the dispersion of the population that belong to different universities. The voluntary nature of the survey and the paucity of institutional promotion at the faculties played havoc with participation. Another limitation of the study was that respondents were students who were aware of the issues raised by the survey and may have chosen socially accepted answers. In general terms, these limitations may have led to an underestimation of non-compliance with the Protocol.

\section{Conclusions}

The findings of this study have a number of practical implications (Table 3). A large majority of the medical students were aware that the obligation of confidentiality also affected the contents of the $\mathrm{CH}(90.6 \%)$. However, they frequently had access to $\mathrm{CHs}$ that were not anonymized, and almost half (43.3\%) possessed copies of non-anonymized patient $\mathrm{CH}$ reports outside the healthcare environment.

Over half of the participants accessed the $\mathrm{CHs}$ of patients on some occasions by using the password of a health professional but $77.2 \%$ of them had not obtained the patients' express consent.

The role of healthcare institutions together with university centres is fundamental to ensure control procedures for the clinical documentation, as well as to promote theoretical training based on a detailed analysis of the Privacy Protocol by means of the study of medical ethics.

\section{Abbreviations}

CH: Clinical history; EMR: Electronic medical record; FYP: Final year project; Q: Questionnaires

\section{Supplementary information}

The online version contains supplementary material available at https://doi. org/10.1186/s12909-021-02689-6.

\section{Additional file 1.}

Additional file 2 .

\section{Acknowledgements}

The authors are grateful to the Spanish Council of Medical Students (CEEM) and all students' representatives of Spanish Medicine Faculties for all their support in the project dissemination, especially the representatives at the University of Córdoba for the interest shown.

\section{Authors' contributions}

All authors contributed to the study conception and design. Material preparation was performed by FL and EGL. Data collection and analysis were performed by RRM and CMBA. The first draft of the manuscript was written by CMBA and all authors commented on previous versions of the manuscript. All authors read and approved the final manuscript.

\section{Authors' information}

CMBA, MD, PhD, is an assistant professor of Legal and Forensic Medicine at the Department of Morphological and Socio-sanitary Sciences and acts as the Medical Degree Coordinator at the Faculty of Medicine and Nursing, University of Córdoba, Spain.

RRM, MD, MPH, is a consultant in Public Health and Preventive Medicine at the Hospital Universitario Reina Sofía of Córdoba. He is an adjunct professor of Preventive Medicine, Department of Medical and Surgical Sciences at the Faculty of Medicine and Nursing, University of Córdoba, Spain.

$\mathrm{FL}, \mathrm{MD}, \mathrm{PhD}$, is an assistant professor of Ophthalmology, Department of Medical and Surgical Sciences, and Vice-Dean of Academic Organization at the Faculty of Medicine and Nursing, University of Córdoba, Spain. $E G L, M D, P h D$, is a full professor of Forensic Medicine, Department of Morphological and Socio-sanitary Sciences, President of the Andalusian Bioethical Committee and Register at the Faculty of Medicine and Nursing, University of Córdoba, Spain.

Funding

Not applicable. 


\section{Availability of data and materials}

The datasets used and/or analyzed during the current study are available from the corresponding author on reasonable request after approval from all the authors.

\section{Declarations}

\section{Ethics approval and consent to participate}

The questionnaire and methodology for this study was performed in accordance with the Declaration of Helsinki and was approved by the Human Research Ethics Committee of the University of Córdoba (Spain) (Ref. No. CEIH-20-21). Informed consent was obtained from all participants. They were told that their participation in the study was voluntary and there was a guarantee of confidentiality and anonymity.

\section{Consent for publication}

Not applicable.

\section{Competing interests}

The authors declare that they have no competing interests.

\section{Author details}

'Sección de Medicina Legal y Forense, Facultad de Medicina y Enfermería, Universidad de Córdoba, 14004 Córdoba, Spain. ${ }^{2}$ Instituto Maimónides de Investigación Biomédica de Córdoba (IMIBIC), Hospital Universitario Reina Sofía, Universidad de Córdoba, Avda. Menéndez Pidal s/n, 14004 Córdoba, Spain. ${ }^{3}$ Sección de Oftalmología, Facultad de Medicina y Enfermería, Universidad de Córdoba, 14004 Córdoba, Spain.

\section{Received: 28 October 2020 Accepted: 25 April 2021}

\section{Published online: 12 May 2021}

\section{References}

1. Snyder L. American college of physicians ethics manual: sixth edition. Ann Intern Med. 2012;156(1):73-104.

2. Sulmasy LS, López AM, Horwitch CA. Ethical implications of the electronic health record: in the service of the patient. J Gen Intern Med. 2017;32(8): 935-9.

3. Peterson JLH. Confidentiality in medicine: how far should doctors prioritise the confidentiality of the individual they are treating? Postgrad Med J. 2018; 94(1116):596-600.

4. Coverdale JH, Roberts LW, Balon R, Beresin EV, Louie AK, Guerrero AP, et al. Professional integrity and the role of medical students in professional selfregulation. Acad Psychiatry. 2016;40(3):525-9.

5. Weiss BD. Confidentiality expectations of patients, physicians, and medical students. JAMA. 1982;247(19):2695-7.

6. Elger BS, Harding TW. Avoidable breaches of confidentiality: a study among students of medicine and of law. Med Educ. 2005;39(3):333-7.

7. Hendelman W, Byszewski A. Formation of medical student professional identity: categorizing lapses of professionalism, and the learning environment. BMC Med Educ. 2014;14:139.

8. Orden SSI/81/2017, por la que se publica el Acuerdo de la Comisión de Recursos Humanos del Sistema Nacional de Salud, por el que se aprueba el protocolo mediante el que se determinan pautas básicas destinadas a asegurar y proteger el derecho a la intimidad del paciente por los alumnos y residentes en Ciencias de la Salud [Spanish Order approved by Agreement at the Meeting of the Committee of Human Resources of the National Health System of the protocol determining certain basic steps aimed at ensuring and protecting the right to privacy of the patient by the students and resident doctors of Health Sciences]. BOE. 2017;31:8277-89.

9. Muramatsu T, Nakamura M, Okada E, Katayama H, Ojima T. The development and validation of the ethical sensitivity questionnaire for nursing students. BMC Med Educ. 2019;19(1):215.

10. Ghodousi A, Abedzadeh M, Ketabi M, Zarean P. Adherence to confidentiality principles from the viewpoint of Iranian dental students: a multicenter study. Eur J Dent Educ. 2018;22(1):e88-93.

11. Organización Médica Colegial of Spain. Código de dentología médica. Guía de etica médica. Madrid: OMC; 2011.

12. Ding N, Yan D, Li H, Ma Y, Wen D. Chinese medical students' agreement with and fulfillment of the physician charter. BMC Med Educ. 2018;18(1):212.
13. Ministerio de Ciencia Innovación y Universidades of Spain. Estadísticas Universitarias. 2015. http://www.educacionyfp.gob.es/servicios-al-ciudadano/ estadisticas/universitaria/estadisticas.html. Accessed 30 Apr 2020.

14. World Federation for Medical Education. Basic Medical Education WFME Global Standards for Quality Improvement. WFME Office. 2015. https:// wfme.org/download/wfme-global-standards-for-quality-improvement-bme/ \#. Accessed 16 Sept 2020.

15. American Board of Internal Medicine, American College of PhysiciansAmerican Society of Internal Medicine. European federation of internal medicine. Medical professionalism in the new millennium: a physician charter. Ann Intern Med. 2002;136(3):243-6.

16. Dasgupta S. Medical genetics ethics case collection: discussion materials for medical students in the genomic era. MedEdPORTAL. 2017;13:10562.

17. European Parliament and Council of European Union. Regulation (EU) 2016/ 679 of the European parliament and of the council on the protection of natural persons with regard to the processing of personal data and on the free movement of such data. OJEU. 2016;119:1-88.

18. Hosseini-Ghavam-Abad L, Asghari F, Bandehagh A, Najafipour S, Bigdeli S. Patient privacy: awareness and attitudes of Iran University of medical sciences medical students. Med J Islam Repub Iran. 2019;33:12.

19. Sturman NJ, Saiepour N. Ethics and professionalism in general practice placements: what should students learn? Aust Fam Physician. 2014;43(7): $468-72$.

20. McGurgan P, Calvert KL, Narula K, Celenza A, Nathan EA, Jorm C. Medical students' opinions on professional behaviours: the Professionalism of Medical Students' (PoMS) study. Med Teach. 2020;42(3):340-50.

21. Eckles R, Meslin E, Gaffney M, Helft P. Medical ethics education: where are we? Where should we be going? A review. Acad Med. 2005;80(12):1143-52.

22. Goldie J, Schwartz L, McConnachie A, Morrison J. The impact of a modern medical curriculum on students' proposed behaviour on meeting ethical dilemmas. Med Educ. 2004;38(9):942-9.

23. Bell HS, Kozakowski SM, Winter RO. Competency-based education in family practice. Fam Med. 1997;29(10):701-4.

24. Møller JE, Clemmensen CR, Mohamed NA, Søndergaard S, Sæther S, Andersen TH, et al. Medical students' perspectives on the ethics of clinical reality. Dan Med J. 2020;67(4):A10190600.

25. Beltran-Aroca CM, Labella F, Font-Ugalde P, Girela-Lopez E. Assessment of doctors' knowledge and attitudes towards confidentiality in hospital care. Sci Eng Ethics. 2019;25(5):1531-48.

26. Lalanda M, Altisent R, Delgado-Marroquin MT. Teaching confidentiality through comics at one Spanish medical school. AMA J Ethics. 2018;20(1): 154-7.

27. Geiderman JM. Observers in the medical setting. Ann Emerg Med. 2017 70(1):86-92.

28. Silver-Isenstadt A, Ubel PA. Medical student name tags: identification or obfuscation? J Gen Intern Med. 1997;12(11):669-71.

29. Moskop JC, Marco CA, Larkin GL, Geiderman JM, Derse AR. From hippocrates to HIPAA: privacy and confidentiality in emergency medicinepart II: challenges in the emergency department. Ann Emerg Med. 2005; 45(1):60-7.

30. Graziano SC, McKenzie ML, Abbott JF, Buery-Joyner SD, Craig LB, Dalrymple $J \mathrm{~L}$, et al. Barriers and strategies to engaging our community-based preceptors. Teach Learn Med. 2018;30(4):444-50.

31. Fraser J. Mentoring medical students in your general practice. Aust Fam Physician. 2016;45(5):270-3.

32. Evans DE, Alstead EM, Brown J. Applying your clinical skills to students and trainees in academic difficulty. Clin Teach. 2010;7(4):230-5.

33. Schiff GD, Bates DW. Can electronic clinical documentation help prevent diagnostic errors? N Engl J Med. 2010;362(12):1066-9.

34. Jones RG, Mehta MM, McKinley RK. Medical student access to electronic medical records in UK primary care. Educ Prim Care. 2011;22(1):4-6.

35. Herrmann-Werner A, Holderried M, Loda T, Malek N, Zipfel S, Holderried F. Navigating through electronic health records: survey study on medical students' perspectives in general and with regard to a specific training. JMIR Med Inform. 2019;7(4):e12648.

36. Pontefract SK, Wilson K. Using electronic patient records: defining learning outcomes for undergraduate education. BMC Med Educ. 2019;19(1):30.

37. Hammoud MM, Margo K, Christner JG, Fisher J, Fischer SH, Pangaro LN Opportunities and challenges in integrating electronic health records into undergraduate medical education: a national survey of clerkship directors. Teach Learn Med. 2012;24(3):219-24. 
38. Guimaraes R, Guimaraes M, Sousa N, Ferreira A. Medical student secrecy, its link to the duty of confidentiality and the right to access and reuse health information. Acta Med Port. 2019;32(1):11-3.

39. Chi J, Bentley J, Kugler J, Chen JH. How are medical students using the electronic health record (EHR)?: an analysis of EHR use on an inpatient medicine rotation. PloS One. 2019;14(8):0221300.

40. Solarte I, Konings KD. Discrepancies between perceptions of students and deans regarding the consequences of restricting students' use of electronic medical records on quality of medical education. BMC Med Educ. 2017; 17(1):55.

41. Brisson GE, Tyler PD. Medical student use of electronic health records to track former patients. JAMA Intern Med. 2016;176(9):1395-7.

42. Baranowski MLH, Stoff BK. Should medical students follow up on skin biopsy results? When education conflicts with patient privacy. J Am Acad Dermatol. 2018;78(6):1229-31.

43. Welcher CM, Hersh W, Takesue B, Stagg Elliott V, Hawkins RE. Barriers to medical students' electronic health record access can impede their preparedness for practice. Acad Med. 2018;93(1):48-53.

44. Rouf E, Chumley HS, Dobbie AE. Electronic health records in outpatient clinics: perspectives of third year medical students. BMC Med Educ. 2008;8:13.

45. Brisson GE, Neely KJ, Tyler PD, Barnard C. Should medical students track former patients in the electronic health record? An emerging ethical conflict. Acad Med. 2015;90(8):1020-4.

46. Foster LM, Cuddy MM, Swanson DB, Holtzman KZ, Hammoud MM, Wallach PM. Medical student use of electronic and paper health records during inpatient clinical clerkships: results of a national longitudinal study. Acad Med. 2018;93(Suppl 11):14-20.

47. DeWitt D, Harrison LE. The potential impact of scribes on medical school applicants and medical students with the new clinical documentation guidelines. J Gen Intern Med. 2018;33(11):2002-4.

48. Beauchamp TL, Childress JF. Principles of biomedical ethics. 7th ed. New York: Oxford University Press; 2009.

49. Calhoun B, Kie J, Morgan A. Health insurance portability and accountability act violations by physician assistant students: applying laws to clinical vignettes. J Physician Assist Educ. 2018;29(3):154-7.

50. Brisson GE, Barnard C, Tyler PD, Liebovitz DM, Neely KJ. A framework for tracking former patients in the electronic health record using an educational registry. J Gen Intern Med. 2018;33(4):563-6.

51. McLaughlin K, Coderre S. Finding the middle path in tracking former patients in the electronic health record for the purpose of learning. Acad Med. 2015;90(8):1007-9.

52. Koppel R, Smith S, Blythe J, Kothari V. Workarounds to computer access in healthcare organizations: you want my password or a dead patient? Stud Health Technol Inform. 2015;208:215-20.

53. Cresswell K, Howe A, Steven A, Smith P, Ashcroft D, Fairhurst K, et al. Patient safety in healthcare preregistration educational curricula: multiple case study-based investigations of eight medicine, nursing, pharmacy and physiotherapy university courses. BMJ Qual Saf. 2013;22(10):843-54.

54. Kuo KM, Chen YC, Talley PC, Huang CH. Continuance compliance of privacy policy of electronic medical records: the roles of both motivation and habit. BMC Med Inform Decis Mak. 2018;18(1):135.

55. Aydin OM, Chouseinoglou O. Fuzzy assessment of health information system users' security awareness. J Med Syst. 2013;37(6):9984.

56. Gaynor M, Omer T, Turner JS. Teaching EHRs security with simulation for non-technical healthcare professionals. J Healthc Prot Manage. 2016;32(1): 84-97.

57. Misto K, Padula C, Dame L, Molloy P, Nimmagadda J. Interprofessional evidence-based strategies to enhance provider and patient interactions during electronic health record use. J Nurses Prof Dev. 2020;36(3):134-40.

58. Pyörälä E, Mäenpää S, Heinonen L, Folger D, Masalin T, Hervonen H. The art of note taking with mobile devices in medical education. BMC Med Educ. 2019;19(1):96

59. DeWane M, Waldman R, Waldman S. Cell phone etiquette in the clinical arena: a professionalism imperative for healthcare. Curr Probl Pediatr Adolesc Health Care. 2019:49(4):79-83.

60. Jonas M, Malpas P, Kersey K, Merry A, Bagg W. Applying ethical and legal principles to new technology: the University of Auckland Faculty of Medical and Health Sciences' policy 'taking and sharing images of patients.'. N Z Med J. 2017;130(1449):30-8.
61. Villamizar PJ, Moreno SM, Moreno F. Management of electronic social networks by students of medicine: the case of publication of photographs with patients and professional medical conduct. Biomedica. 2016;36(1):140-8.

62. Williams F, Oke A, Zachary I. Public health delivery in the information age: the role of informatics and technology. Perspect Public Health. 2019;139(5): 236-54.

63. Barnhoorn P, Bolk J, Ottenhoff-de Jonge M, van Mook W, de Beaufort A Causes and characteristics of medical student referrals to a professional behaviour board. Int J Med Educ. 2017;8:19-24.

64. Reddy ST, Farnan JM, Yoon JD, Leo T, Upadhyay GA, Humphrey HJ, et al. Third-year medical students' participation in and perceptions of unprofessional behaviors. Acad Med. 2007;82(Suppl 10):35-9.

65. Beltran-Aroca CM, Girela-Lopez E, Collazo-Chao E, Montero-Perez-Barquero M, Munoz-Villanueva MC. Confidentiality breaches in clinical practice: what happens in hospitals? BMC Med Ethics. 2016;17(1):52.

66. Minicuci N, Giorato C, Rocco I, Lloyd-Sherlock P, Avruscio G, Cardin F. Survey of doctors' perception of professional values. Plos One. 2020;15(12): e0244303.

\section{Publisher's Note}

Springer Nature remains neutral with regard to jurisdictional claims in published maps and institutional affiliations.
Ready to submit your research? Choose BMC and benefit from:

- fast, convenient online submission

- thorough peer review by experienced researchers in your field

- rapid publication on acceptance

- support for research data, including large and complex data types

- gold Open Access which fosters wider collaboration and increased citations

- maximum visibility for your research: over $100 \mathrm{M}$ website views per year

At BMC, research is always in progress.

Learn more biomedcentral.com/submissions 